Review

\title{
Current Knowledge of Medicinal Mushrooms Related to Anti-Oxidant Properties
}

\author{
Shifa Shaffique ${ }^{1}$, Sang-Mo Kang ${ }^{1}$, Ah-Yeong Kim ${ }^{2}$, Muhammad Imran ${ }^{1}$, Muhammad Aaqil Khan ${ }^{1} \mathbb{D}$ and \\ In-Jung Lee ${ }^{1, *}$ \\ 1 Department of Applied Biosciences, Kyungpook National University, Daegu 41566, Korea; \\ Shifa.2021@knu.ac.kr (S.S.); kmoya@hanmail.net (S.-M.K.); m.imran02@yahoo.com (M.I.); \\ aqil_bacha@yahoo.com (M.A.K.) \\ 2 Gyeonsangnam-Do Agricultural Research \& Extension Services, Jinju 52733, Korea; Kay0623@korea.kr \\ * Correspondence: ijlee@knu.ac.kr
}

check for

updates

Citation: Shaffique, S.; Kang, S.-M.; Kim, A.-Y.; Imran, M.; Aaqil Khan,

M.; Lee, I.-J. Current Knowledge of Medicinal Mushrooms Related to Anti-Oxidant Properties.

Sustainability 2021, 13, 7948.

https: / / doi.org/

$10.3390 /$ su13147948

Academic Editor: Dario Donno

Received: 23 March 2021

Accepted: 13 July 2021

Published: 16 July 2021

Publisher's Note: MDPI stays neutral with regard to jurisdictional claims in published maps and institutional affiliations.

Copyright: (C) 2021 by the authors. Licensee MDPI, Basel, Switzerland. This article is an open access article distributed under the terms and conditions of the Creative Commons Attribution (CC BY) license (https:// creativecommons.org/licenses/by/ $4.0 /)$.

\begin{abstract}
Background: A renewed focus on medicinal mushrooms has brought forth a sustainable health dimension. Conventional health strategies are insufficiently integrated with sustainable health promotion. The health-promoting outcome of mushrooms has fascinated many groups during the past few years because of various primary and secondary metabolites in different cellular components. They contain many bioactive metabolites, including proteins (cytokines, ergothioneine), fibers, moisture, carbohydrates (uronic acid), folate, thiamine, ascorbic acid, vitamin D, calcium, potassium, polysaccharides (G. lucidum polysaccharides, alpha and beta glucans, and lentinan) polyketides, polyphenols (Protocatechuic acid, inonoblins A-vanillic acid, phelligridins D, E, and G, hydroxybenzoic acid, gallic acid, tannic acid, hispidine, gentisic acid, and tocopherol), nucleotides (adenosine, cordycepin), lovastatin, steroids, alkaloids, and sesquiterpenes. Objective: This study was conducted to gather information on the current knowledge of medicinal mushrooms, with respect to their antioxidant properties. Conclusions: The results indicated that mushrooms are a promising source of natural antioxidants. Of all mushrooms, the Ganoderma tsugae Murill exhibited an excellent antioxidant potential of $93.7-100 \%$ at $20 \mathrm{mg} / \mathrm{mL}$.
\end{abstract}

Keywords: medicinal mushrooms; antioxidant; metabolic disorder

\section{Introduction}

Increasing awareness of functional foods has created a great impact worldwide. It is a health tradition to heal with fungi, i.e., mushrooms, which are known as medicinal mushrooms. A popular trend in eastern and western culture is to promote the beneficial health properties of mushrooms [1]. Mushrooms have been well known for centuries for their many medicinal properties [2]. They are a good source of dietary components and have many biologically active compounds; hence, they are labeled as medicinal mushrooms due to their numerous pharmacological activities [3]. There are approximately $1,400,000$ species of mushroom on Earth, and only $10 \%$ are known by their species and metabolites [4]. Medicinal mushrooms contain potentially active constituents. Medicinal mushrooms contain the pharmacological potential to treat various types of diseases, such as heart diseases, diabetes, tumor, sepsis, immunomodulatory disorders, various organic lesions, and metabolic disorders [5,6]. Various dietary nutrients make mushrooms edible [7].

Oxygen is associated with the aerobic life cycle, representing life sustainability. Endogenous body metabolism, pathophysiology, and exogenous ultraviolet rays cause the triplet oxygen in the physiological system. These are free electrons present in their orbital spaces and cause oxidation stress [8,9]. Physiologically, the endogenous system of the body can scavenge free radicals. If the body system fails to fight against free radicals, oxidative stress ensues, which can cause damage to various organs as shown in Figure $1[10,11]$. The 
antioxidant status in humans reflects the dynamic balance between peroxidation and antioxidant defense system. Therefore, it is critical that natural substances with the capability of scavenging free radicals are accessible as a pharmacological resource [12,13]. Medicinal mushrooms can achieve these aims, as they contain total phenolic content flavonoids and polysaccharides, cytokines, and lentinan that can reduce oxidation stress [14-18].

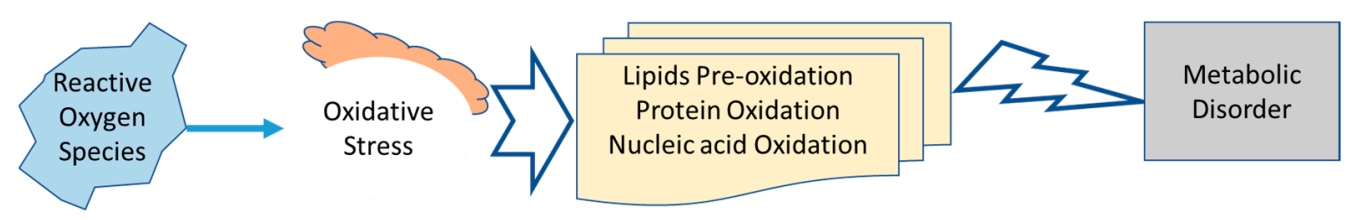

Figure 1. Oxidative stress and its consequences.

\section{Material and Methods}

We downloaded and studied the paper using the search words "medicinal mushrooms, antioxidant, and metabolic disorders". There is no selection of time. We collected all data, including the human model, rodent model, case-control study, cohort study, and scientific reports, using Google Scholar as a search engine up to May 2021. We excluded conference papers and data that were not in English. A total of $n=68$ studies including (31 vitro, 14 in vivo) submerged multinational studies, case studies, and interventional studies examining 174 mushrooms were reviewed.

\section{Review}

Mushrooms have been used as medicine and food for many years. The lower fat and cholesterol portion and maximum protein and fiber content raises their biomedical importance. The present paper reviews the integrated current medicinal potential with basic science related to antioxidant capacities $[19,20]$.

\section{Current Knowledge}

Medicinal mushrooms have documented potent antiviral, anti-inflammatory, and antibacterial potential against Gram-positive and -negative bacteria. Some species include Basidiomycota, Agaricus blazei Murill (AbM), Hericium erinaceus (HE), and Grifola frondosa (GF). Basidiomycota species are important among medicinal mushrooms that exhibit the potential to treat inflammation. In vivo, it reduces bacteremia and mortality rate in Wistar albino rats. It might be used as an add-on remedy for COVID-19 to treat the superinfection related to pneumonia and corona virus. Therefore, it is suggested that it might be used as a prophylactic agent against coronavirus, due to its strong therapeutic background and presence of polysaccharides (beta glucans), which protect against infection. However, studies on a larger scale and with significant scientific proof are required. The mechanism of action is immunomodulatory [21].

A recent scientific report has revealed the prebiotic effect of Cantharellus cibarius polysaccharide (CCP) mushroom, which is related to the golden chanterelle species. An in vivo study was conducted in Eskisehir Osmangazi University, Turkey, to estimate the effect of Cantharellus cibarius polysaccharide. Wistar albino rats were divided into three groups, and each group contains seven $(n=7)$ rats. Animals were administered inulin and $\mathrm{CCP}$, and comparison was made based on the prebiotic index. The prebiotic index is considered the biomarker to access the prebiotic potential. The results show that the treatment group with CCP has the highest Lactobacillus count, $1.84 \times 109 \mathrm{CFU} / \mathrm{mL}$, and the lowest Clostridium count, $0.03 \times 109 \mathrm{CFU} / \mathrm{mL}$. The prebiotic index is 9.39, which is higher than the control group [22].

\section{Antioxidant Potential}

M. Kozarski explored a study for the molecular characterization-based workflow for polysaccharide extracts of Agaricus bisporus, Agaricus brasiliensis, Phellinus linteus, and 
Ganoderma lucidum. The results indicated that from FTIR, polysaccharide extracts of mushrooms contained $\alpha$ - and $\beta$-glucans, uronic acid, and phenolic compounds. G. lucidum showed a maximum of $83 \%$ glucans and the antioxidant activity of Ganoderma lucidum was greater than those of other mushrooms extracts. The study suggests a positive correlation between the glucan level, reducing power, and polyphenol components [23]. A study was conducted on 14 species of Basidiomycetes mushroom cultures, including C. disseminatus, Lepista personata, Trametes versicolor, Pleurotus ostreatus, C. micaceus, Hypholoma fasciculare, Pholiota alnicola, Marasmius oreades, Coprinus comatus, Schizophyllum commune, Lentinus edodes, Suillus luteus, Volvariella bombycine, and Stropharia coronilla. The mycelial samples were tested on days 7, 14, 21, and 28. Of the 14 species, Pholiota alnicola, Schizophyllum commune, Trametes versicolor, Volvariella bombycina, Suillus luteus, Lentinus edodes, and Lepista personata showed more than $20 \%$ antioxidant potential. However, there is a need for this study to be replicated to confirm the results [24]. J. L. Mau et al. estimated the antioxidant potential of methanolic extracts of medicinal mushrooms, including Ganoderma tsugae, Ganoderma lucidum, and Coriolus versicolor, at different concentrations of $0.6,0.64,2.4,4,14 \mathrm{mg} / \mathrm{mL}$, using the 2,2'-diphenyl-1-picrylhydrazyl radical (DPPH) method. Results indicate that $G$. tsugae and G. lucidum contain the best reducing power in all concentrations to fight against free radicals, due to their phenolic contents [25]. In 2008, M.Y. Kim et al. determine the total phenolic contents and antioxidant potential of five edible medicinal mushrooms. The total phenolic contents were measured using high-performance liquid chromatography (HPLC), whereas antioxidants were measured using the DPPH method. Studies show that the average concentration of total phenolic components was $326 \mu \mathrm{g} / \mathrm{g}$. Among all species, Agaricus bisporus contains the greatest antioxidant potential; i.e., a $78 \%$ positive correlation was found between phenolic contents and antioxidant potential [26]. In Brazil, an experiment was carried out to determine the antioxidant potential of a methanolic extract of shiitake and oyster mushrooms, using the 1,3-diethyl-2-thiobarbituric acid method. The result indicates the excellent scavenging property of oyster mushrooms $(54.3 \%)$ at $40 \mathrm{mg} \mathrm{mL}^{-1}$. This antioxidant potential is due to total phenolic content, and the chelating effect on ferrous ions was maximum $45.6-81.6 \%$ at $1.6 \mathrm{mg} \mathrm{mL}^{-1}$ [27].

Later the antioxidant potential of five methanolic extracts of ear mushrooms, including red, black, jin, snow, and silver ears, following the DPPH method was determined. The results indicated that methanolic extracts contain the following bioactive components: tocopherol, polyphenol, and ascorbic acid. All mushrooms of the ear family showed maximum antioxidant potential except for the silver ear mushroom. The snow ear showed maximum antioxidant potential $[17,28]$. All mushrooms are good chelators against ferrous ions [15]. The antioxidant potential of ethanolic extracts of Laetiporus sulphureus at different concentrations $(100,200,400$, and $800 \mu \mathrm{g} / \mathrm{mL})$ were recorded. It contained the bioactive metabolites, phenols and flavonoids. The total phenolic content present in the ethanolic extract was $14.2 \pm 0.12$ (quercetin equivalents $\left(\mu \mathrm{g} \mathrm{mg}{ }^{-1}\right)$ ). The results showed a positive correlation between polyphenol and antioxidant potential. It showed $14 \%, 26 \%, 55 \%$, and $86 \%$ absorbance, according to the DPPH method compared with ascorbic acid. It also inhibits the growth of various microorganisms, such as bacteria and fungi [29]. An experiment was followed to evaluate the antioxidant potential of 10 medicinal mushrooms, including Morchella hortensis, Meripilus giganteus, Armillaria mellea, Morchella costata, Morchella elata, Morchella rotunda, Paxillus involutus, Morchella esculenta var. vulgaris, Pleurotus eryngii, and Pleurotus ostreatus, via the DPPH method. Among the mushrooms, M. elata possessed significant antioxidant potential toward free radicals [30]. A research on the methanolic extracts of Inonotus obliquus was conducted to estimate its antioxidant potential. The methanolic extracts showed maximum inhibitory potential against Trolox-equivalent antioxidant capacity and 1,1-diphenyl-2-picrylhydrazyl-free radicals. Results indicate that it possesses significant antioxidant potential due to polyphenols, such as inonoblins $\mathrm{A}-\mathrm{C}$ and phelligridins D, E, and G. [31]. An experiment was designed to dose-dependently analyze the antioxidant and hepatoprotective pattern of Lentinus edodes, a culinary mushroom, on mice. Acid hydrolysis residues were used and administered 200, 400, and $600 \mathrm{mg} / \mathrm{kg}$ body 
weight mushrooms. A liver function test, liver enzymes, and a renal function test were taken as a gold-standard biomarker for the functional recovery of hepatocytes. Results showed that culinary mushrooms are healthy as food and medicine for the liver [32]. An in vitro study experiment was done in Iran to estimate the antioxidant potential of methanol and ethyl acetate extracts from two medicinal mushrooms, Cantharellus cibarius and Pleurotus porrigens, via the DPPH method. Methanolic extracts showed significantly more antioxidant activity than ethyl acetate extracts [33]. A study was carried out on the hot water extracts of the following medicinal mushrooms: Agaricus, Antrodia, Auricularia, Coprinus, Cordyceps, Hericium, Grifola, Ganoderma, Lentinus, Phellinus, and Trametes. Due to polyphenolic compounds and polysaccharides, the results indicated that all mushrooms possessed the highest antioxidant potential. Among all mushrooms, Ganoderma is more potent antioxidant mushroom [34].

A comparative study between the wild and cultivated mushrooms of Ethiopia and their antioxidant potential were recorded. For this study, two cultivated mushrooms- $P$. ostreatus and L. edodes-and five wild mushrooms-A. campestris, L. sulphureus, T. clypeatus, T. letestui, and T. microcarpus-were selected. Results indicate that $A$. campestris possesses significant antioxidant potential at EC50 mg/mL. The antioxidant activity is due to the presence of total phenolic contents. Wild mushrooms are more potent antioxidants compared with cultivated mushrooms [35]. The Polyporoid species of medicinal mushrooms that are native to Poland. The five mushrooms, namely, Daedaleopsis confragosa, Fomitopsis pinicola, Gloeophyllum sepiarium, Laetiporus sulphureus, and Piptoporus betulinus, were studied. Their chemical constituents were analyzed by HPLC. The results showed that it contains protocatechuic, vanillic, and hydroxybenzoic acids, a potent phenolic compound of $17.7-90.0 \mu \mathrm{g} / \mathrm{g}$, to which it contains significant antioxidant potential. Two medicinal mushrooms, Fomitopsis pinicola and Gloeophyllum sepiarium, contained high amounts of phenolic compounds and exhibited significant antioxidant potential. Their antioxidant activities were measured using the FRAP method, with values of 55.79 and $87.82 \mathrm{mmol}$, respectively [28]. A study was conducted on the antioxidant potential of Pleurotus eryngii via the DPPH method. The results revealed that it showed an excellent antioxidant activity to scavenge free radicals and possessed reducing power due to its phenolic content. It also contains ergothioneine due to its use as a functional food. Ergothioneine is a naturally occurring amino acid that inhibits the production of oxidant by metal ions, scavenging hydroxyl, and hypochlorous acids [36]. The University of Calcutta conducted a study to review the medicinal properties of mushrooms. The study revealed that medicinal mushrooms contain bioactive compounds, such as flavonoids, tocopherols, ascorbic acid, carotenoids, and polysaccharides. The six medicinal mushrooms, namely, Fistulina hepatica, Pleorotus squarrosulus, Polyporus grammocephalus, Phellinus linteus, Austreus hygrometricus, and Macrocybe gigantea, showed significant antioxidant potential, making them useful in treating various diseases [37]. The Defense Institute of Bio-Energy Research conducted a study to evaluate the antioxidant potential of different concentrations of the medicinal mushroom, Ganoderma lucidum, native to the Himalayas. Its activity was assessed using 1,1-diphenyl-2-picrylhydrazyl, 2,2' -azinobis (3-ethylenebenzothiazoline-6sulphonic acid), and the hydroxyl radical method. Results indicated that the methanolic extracts of wild G. lucidum, with minimum $\mathrm{IC}_{50}$ values of $0.953 \pm 0.040,0.690 \pm 0.014$, and $3.295 \pm 0.027 \mathrm{mg} / \mathrm{mL}$, showed significant antioxidant potential [38]. A study was conducted on the aqueous ethanolic extract of Volvariella volvacea. In vivo, this study was conducted on a DLA cell line-induced solid tumor, EAC cell line-induced ascites tumor mouse models; in vitro, it was conducted using the DPPH method. The results indicated that it possessed significant antitumor and antioxidant potential [39]. The five medicinal mushrooms, including Volvariella volvacea, Pleurotus ostreatus, Lentinula edodes, Ganoderma lucidum, and Auricularia polytricha, were selected to estimate their nutritional value and antioxidant capacity. The results showed that mushrooms contain protein, carbohydrate, ash, moisture, and phenolic components in various amounts. It also indicated that $G$. lucidum has high phenolic contents and significant antioxidant potential, thus making it 
a good functional food [40]. The medicinal mushroom, Ganoderma tsugae Murrill, were checked at different concentrations. The results indicated that, due to polysaccharides, it possessed the best scavenging ability at $20 \mathrm{mg} / \mathrm{mL}$ using 1,1-diphenyl-2-picrylhydrazyl radicals increased to $93.7-100 \%$. Therefore, it can be consumed as a food with a good source of antioxidants [41].

After that, a study conducted on the ethanolic extract of Morchella conica Pers at $160 \mu \mathrm{gmL}$, using the butylated hydroxyanisol method showed a $98.9 \%$ antioxidant potential [42]. The methanolic extracts of Ganoderma tsugae Murrill were accessed for their oxidant potential. The results indicated a significant antioxidant potential of $96.8 \%$ and $93.6 \%$ at $20 \mathrm{mg} \mathrm{mL}^{-1}$, due to the presence of phenolic components, beta carotene, and ascorbic acid [43]. The hot water extract of Ganoderma tsugae Murrill in four forms, namely, mature, baby Ling chih, mycelia, and fermentation-filtrated hot water extracts, were analyzed. Mature and baby Ling chih showed high antioxidant activities of $78.5 \%$ and $78.2 \%$ at $20 \mathrm{mg} / \mathrm{mL}$, respectively. Their antioxidant activity was due to the presence of phenols and was conducted using the DPPH method [44]. For the Leucopaxillus species, which are native to northeast Portugal, its antioxidant activity was measured by the reducing power assay and DPPH method. Negative linear regressions were seen between flavonoids, which increased with the mycelia of mushroom and antioxidant activity [45]. The three mushrooms, Pleurotus ferulae, Clitocybe maxima, and Pleurotus ostreatus gray, were selected for antioxidant study. Their antioxidant potential was measured between the ethanolic and hot water extracts. The antioxidant activity was conducted using the DPPH method. The results showed that they contain phenolic contents of 5.10-11.1 mg, making them capable of fighting the oxidative stress system [46]. The eight species of medicinal mushrooms, including Ganoderma lucidum, Hypsizygus marmoreus, P. ostreatus, P. nebrodensis, Lentinus edodes, Pleurotus eryngii, Flammulina velutipes, and Hericium erinaceus, were selected to compare the antioxidant potential using the DPPH method. The results indicated that the $H$. erinaceus polysaccharide contains significant antioxidant potential due to polysaccharides. Further study was also conducted to assess the effectiveness of medicinal mushrooms in MCF-7 breast cancer cell lines. The results showed that G. lucidum polysaccharides exhibited significant inhibition in the MCF-7 cell line. The study suggests that it can be a good therapeutic agent for cancer and oxidative damage [47]. The antioxidant potential of Cordyceps taii, which is a medicinal mushroom present in Taiwan, was subjected under study. The study revealed that, due to the presence of polysaccharides, it possesses antioxidant potential to scavenge free radicals. After in vitro evaluation, an in vivo study was planned on a d-galactose-induced aging mouse model. The aqueous extract of the mushroom was used. Results showed that due to polysaccharides, it increases the production of the endogenous antioxidant enzymes and inhibits lipid peroxidation. It is a potent antioxidant medicinal substance that closely relates to enhancing immune system performance [48]. An in vitro study on the methanolic extracts of Pleurotus porrigens and Hygrocybe conica were carried out to determine the antioxidant potential and reducing power. Results indicated that Hygrocybe conica showed the highest (94\%) chelating effect at $20 \mathrm{mg} / \mathrm{mL}$ and a potent antioxidant (85\%) effect due to total phenolic components [49]. The wild mushrooms, due to containing many bioactive compounds, such as polyphenols, tocopherols, ascorbic acids, and carotenoids possess antioxidant potential. Mushrooms inhibit oxidative stress and promote the scavenging of free radicals [50]. A submerged cultivation study of a medicinal Basidiomycetes mushroom, containing active metabolites, including polysaccharides, proteins, polyphenols, polyketides, triterpenoids, steroids, alkaloids, and nucleotides, due to its active metabolites, revealed that it acted as the best antioxidant [51].

\section{Metabolic Disorder}

A scientific investigation and phytochemical screening of four traditionally used medicinal mushrooms A. auricular, Fomes fomentarius, Ganoderma lucidum, and Coprinus comatus was conducted. The results showed the presence of chlorogenic acid in $A$. auricular. Chlorogenic acid, an ester of quinic and caffeic acid, acts as an intermediate for 
lignin biosynthesis in HaCaT cells. It has Hepatoprotective, antihypertensive, and antiinflammatory components. The presence of chlorogenic acid makes the mushrooms unique and a possible gateway for its utilization in various metabolic disorders. The mushrooms also contain ergothioneine, ergosterol, polyketides, lentinan, monacolins, statins, pleuromutilin potassium, and calcium in favorable amounts. Its mechanism of action is by inhibiting the HMG-COA reductase pathway, which is the rate-limiting step in cholesterol synthesis. All Auricularia species contain the highest antioxidant index and are valuable in treating liver disorders [52]. A study was conducted to evaluate the biological activities of medicinal mush-rooms. The results indicated that it contained a significant immune-modulator, anti-microbial, antitumor, and antioxidant activities. Phellinus rimosus, Ganoderma, and Agaricus bisporus possess antioxidant potential due to their active metabolites. They are rich sources of folate, thiamine, vitamin C, vitamin D, polysaccharides, protein, glycoproteins, peptides, and lentinan. Lentinula edodes possess lentinan, which causes tumor regression [53].

A study was conducted in South India to explore the importance of four medicinal mushrooms Pleurotus pulmonarius, Phellinus rimosus, Ganoderma lucidum, and Pleurotus florida. An in vivo study was designed using a rodent model to observe the effect of medicinal mushroom as an anticarcinogen. The hot water, methanol, ethyl acetate, and aqueous extracts were checked against antioxidant and anticarcinogenic effects. The study shows that it inhibits the Daltons Lymphoma Ascites cell-induced solid tumor model and Ehrlich's Ascites Carcinoma cell-induced ascites tumor in the animal model. Anticarcinogen activity was higher in ethyl acetate extracts than in others. In contrast, the methanolic extract showed the best antioxidant potential. Thus, these mushrooms would be a profound source of nutrition and medicine as well [54]. Diabetes mellitus is a metabolic syndrome characterized by intercellular hypoglycemia and extracellular hyperglycemia. Medicinal mushrooms regulate blood hemostasis, increase insulin activity, and activate the aldose reductase inhibitory pathway. In an in vivo experiment, the nicotinamide- and streptozocin-induced rat models were treated with sixteen crude extracts of medicinal mushrooms (Ganoderma lucidum, Sensu lato, Grifola frondosa, Hericium erinaceus, Inonotus obliquus, Lentinula edodes, Phellinus spp., Tremella fuciformis, Cordyceps sinensis, Cordyceps militaris, Cordyceps spp., Auricularia auricula-judae, Coprinus comatus, Agaricus bisporus, and Agaricus campestris). Results showed the significant antidiabetic effect of medicinal mushrooms [55]. The nonalcoholic fatty liver disorder (NAFLD) is a metabolic syndrome positively linked with type 2 diabetes mellitus and cardiovascular disorders. Currently, there is no medicine that can treat NAFLD. In 2021, a study was conducted that showed medicinal mushrooms, such as Poria cocos wolf, Gomphidius rutilus, and frondose, as therapeutically important in treating fatty liver disease. Mushrooms are scientifically important because of their use in treating metabolic syndromes. A study was conducted in the University of Ibadan, Oyo state, Nigeria, on the ethanolic extract of Ganoderma lucidum. This was an in vivo evaluation of 30 male Wistar albino rats, using the ethanolic extract of GEE minimized oxidative stress. The results showed a dose-dependent reduction in the levels of serum TAG, CHO, and blood glucose. The study revealed that ethanolic extracts are therapeutically important in easing metabolic syndromes [56]. At the Alexandria University, Egypt, an in vivo evaluation was conducted on 48 male albino obese rats to assess the effect of mushrooms in weight reduction and health improvement. Two mushrooms, Avena sativa and Pleurotus ostreatus, in a powder form, were mixed in four food products, including soup, kofta, pizza, and kabab. The nutritionist results confirmed that mushrooms are significantly important in reducing weight and controlling metabolic syndrome, as compared with wheat flour [57]. Various recent studies favor mushrooms as significantly valuable in treating various disorders because of their biological activities, such as anticancer, antioxidant, and anti-hyperuricemia, and as a healthy food source. The ethanol, methanol, chloroform, and aqueous extracts of four medicinal mushrooms Astraeus hygometricus, Agaricus sylvaticus, Ganoderma lucidum, and Pleurotus pulmonarius were checked. Molecular characterization showed that they contain glyceraldehyde-3-phosphate dehydrogenase-like protein, which 
lowers glucose level. Among all mushrooms, the G. lucidum possess significant antidiabetic activity. Tylopilus ballouii, Pleurotus sajor-caju, and Ganoderma lucidum were assessed for their anti-inflammatory potential in various rodent models. Various studies showed that it contains adenosine and cordycepin, which has anti-inflammatory potential [58]. Ascomycetes and Basidiomycetes mushrooms were checked for their therapeutic functionality. Huitlacoche is an edible mushroom that contains ergothioneine ranging from $0.40 \pm 0.03$ to $5.54 \pm 0.26 \mu \mathrm{mol} / \mathrm{L}$. Ergothioneine is a bioactive compound that is pharmacologically important in various disorders, such as Alzheimer disease, metabolic syndrome, skin ailments, and eye infections. It acts by inhibiting oxaliplatin development in the ganglion [59]. Mushrooms, namely, Boletus edulis, P. salmoneostramineus, and Aspergillus brasiliensis, contain polyphenol, illudane sesquiterpenoids, vitamin A, hispidine, sterol, and carotenoids, which prevent cellular damage, and thus have antioxidant, antibacterial, and antifungal potential [60]. Ganoderma lucidum, which is a Chinese medicinal mushroom, possesses many pharmacological activities, serving as an immunomodulator and preventing several metabolic disorders and organic lesions. A case-control study on humans was conducted, in which 18 healthy males were selected to observe the effectiveness of a mushroom diet. Various serological parameters were accessed before and after the experiment. The results showed that there is no oxidative plasma difference between the control and treatment groups after four weeks of supplementation. No hepatorenal toxicity was observed in the treatment groups. However, a slightly lower level of cholesterol was seen, which may be due to its active bioconstituent-triterpenes [61]. An in vivo study was conducted in Japan to estimate the potential of medicinal mushrooms against various metabolic disorders and their immunomodulatory effects. The induction of methylcholanthrene for 72 weeks produced a tumor in 36 mice. This study showed that Hypsizygus marmoreus possesses immune potential, and only 3 of the 36 mice were unaffected, while others showed significant antitumorigenic effects due to EA6-a low molecular weight protein-bound polysaccharide [7].

\section{Results}

This study was undertaken to explore the current knowledge of medicinal mushrooms with respect to antioxidants from water, ethanol, methanol, ethyl acetate, dried form, and chloroform extracts of fruiting bodies of mushrooms, naturally growing in different geographical locations of the world. It revealed that all mushroom species exhibit moderate to excellent antioxidant potential as shown in Table 1 below.

Compared with wild and cultivated mushrooms, our study suggests that wild mushrooms are a good source of functional antioxidant food. All mushroom under study contained variable amounts of bioactive metabolites and nutrients, such as polysaccharide, flavonoids, phenols, vitamin D, vitamin C, folate, nucleotides, ergothioneine, lentinan, selenium, copper, zinc, steroids, alkaloids, terpenoids, proteins, statin, and moisture content. The bioactive metabolites are good for health sustenance and might be potent therapeutic agents against various metabolic disorders. Thus, mushrooms can be used as a functional food.

All ear mushrooms (red, black, Jin, snow, etc.) possessed the highest number of phenolic components and antioxidant capacity. Except for the silver ear mushroom, the snow ear mushrooms showed $49.7 \%$ maximum antioxidant activity. Of all mushrooms, the Ganoderma tsugae Murill exhibited an antioxidant potential of $93.7-100 \%$ at $20 \mathrm{mg} / \mathrm{mL}$. Other mushrooms also exhibit good antioxidant potential. Gloeophyllum sepiarium possessed 17.7-90.0 $\mu \mathrm{g}$ phenolic content and 55.79-87.82\% antioxidant activity. Laetioporus sulphureus and Hygrocybe conia showed $85 \%$ absorbance compared with ascorbic acid. Oyster mushrooms showed $54.3 \%$ antioxidant potential at $40 \mathrm{mg} / \mathrm{mL}$ and a chelating effect of $45.6-81.6 \%$ at $1.6 \mathrm{mg} / \mathrm{mL}$. Agaricus bisporus possessed $78 \%$ antioxidant capacity and a $326 \mu \mathrm{g} / \mathrm{g}$ phenolic compound. 
Table 1. Studies on the effect of mushrooms, compounds, and their actions.

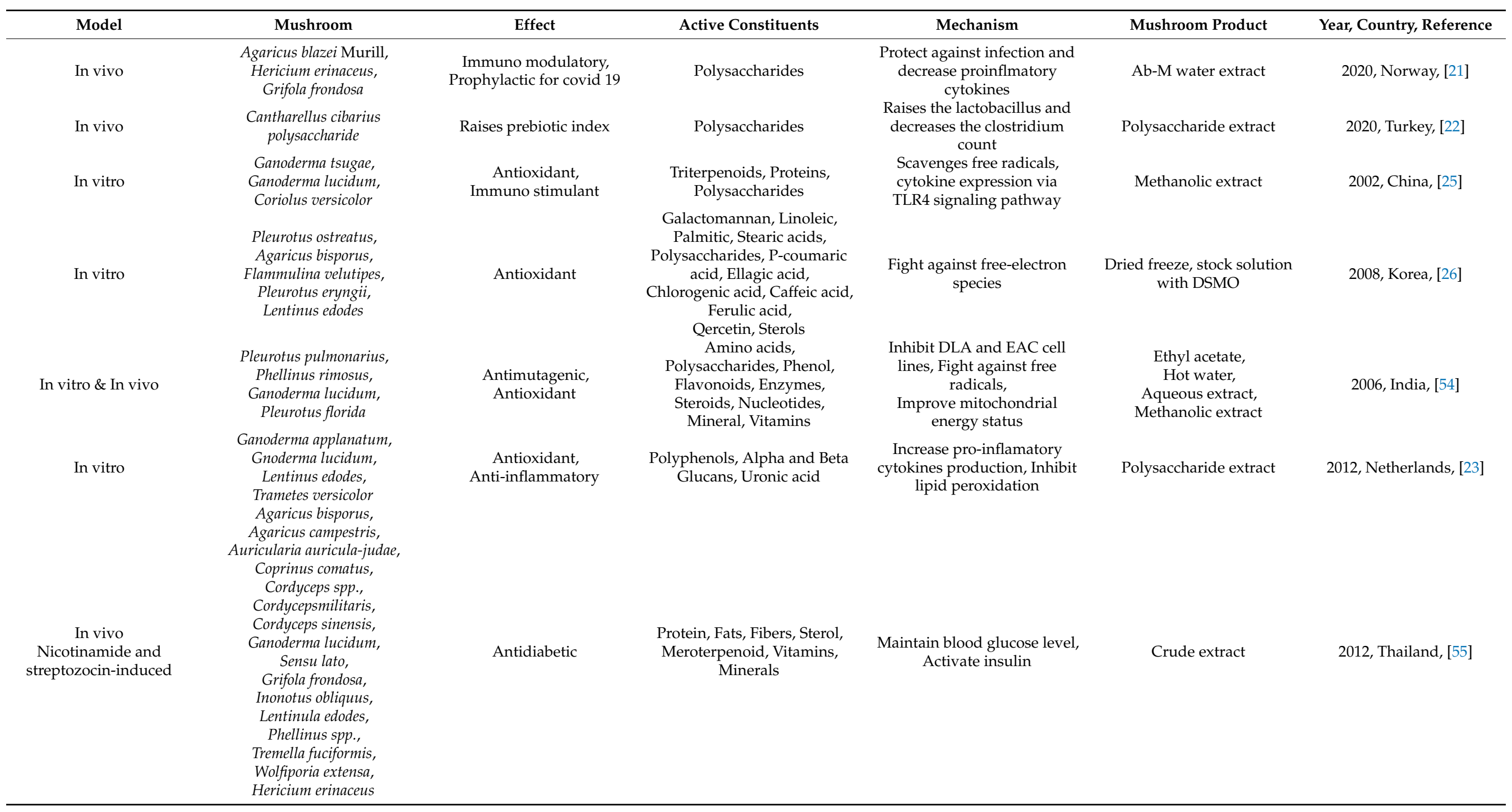


Table 1. Cont.

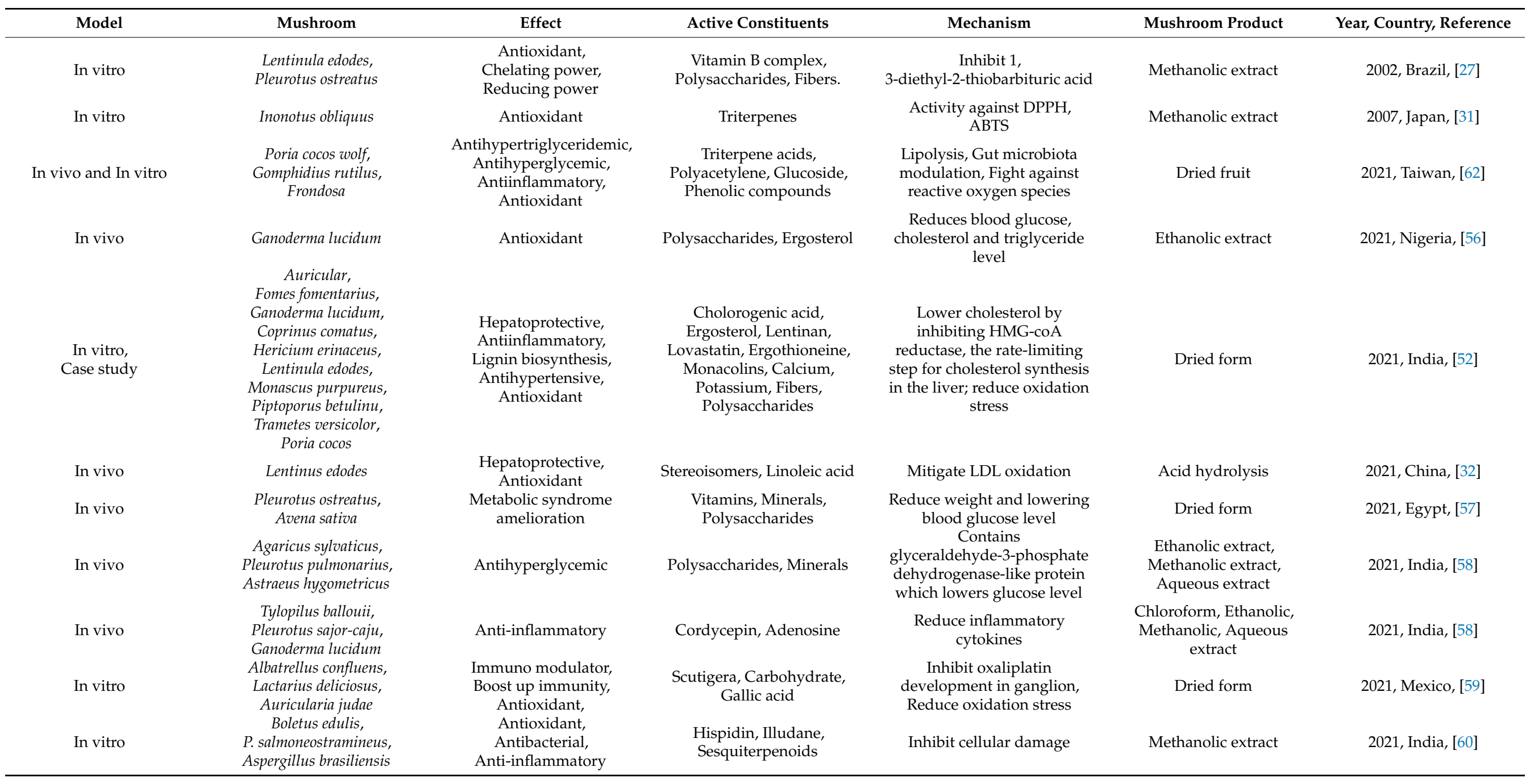


Table 1. Cont.

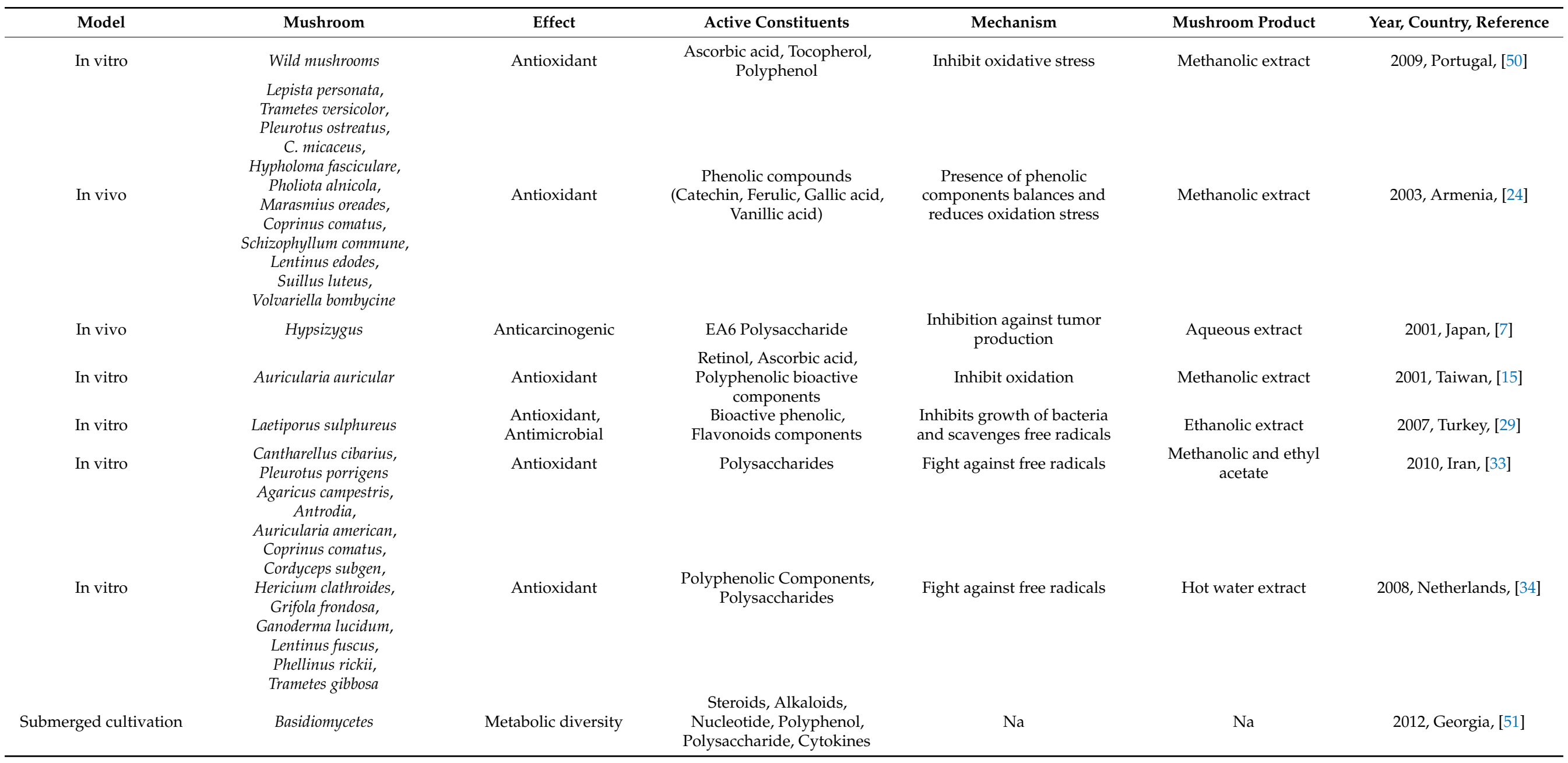


Table 1. Cont.

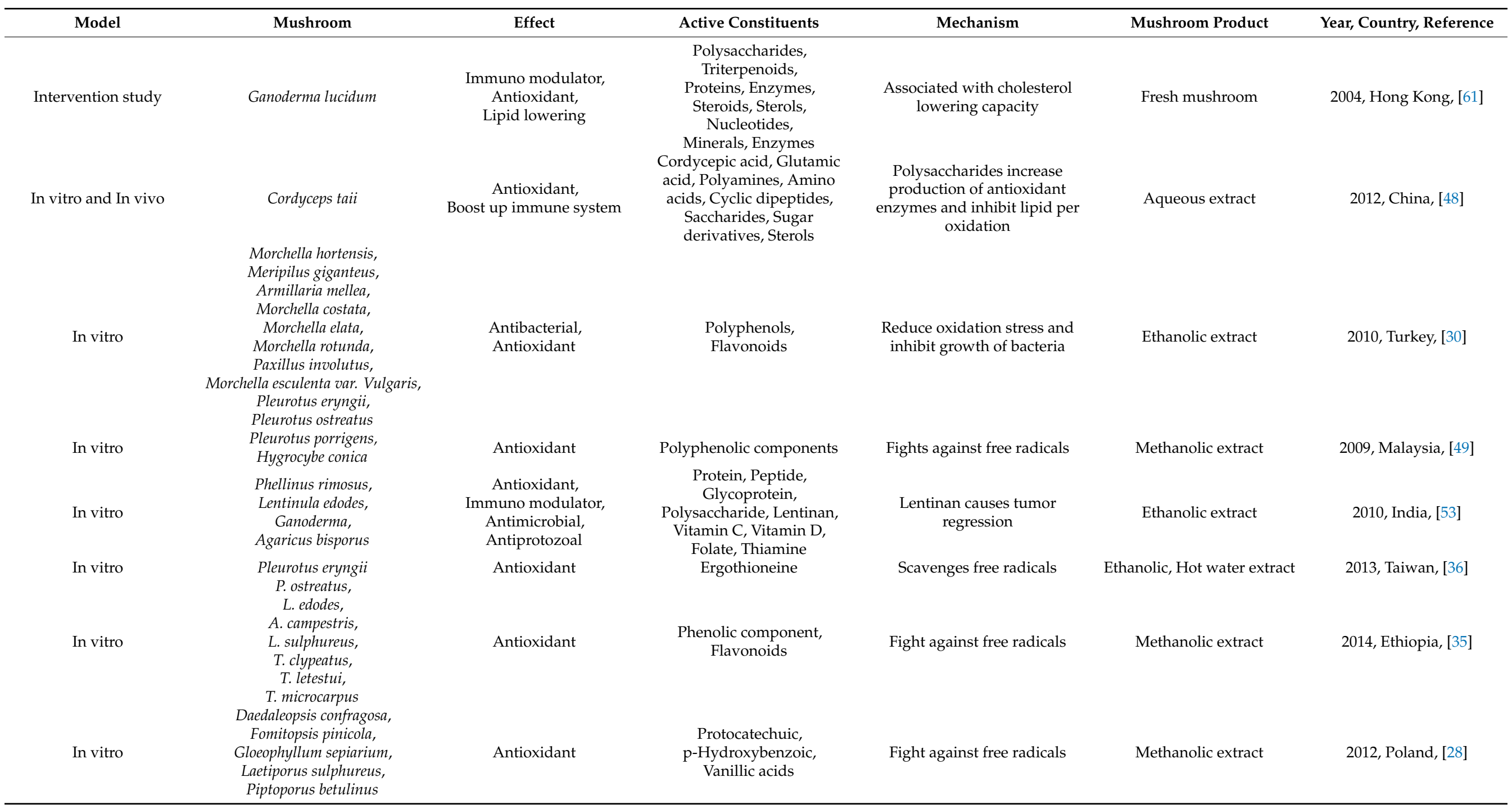


Table 1. Cont.

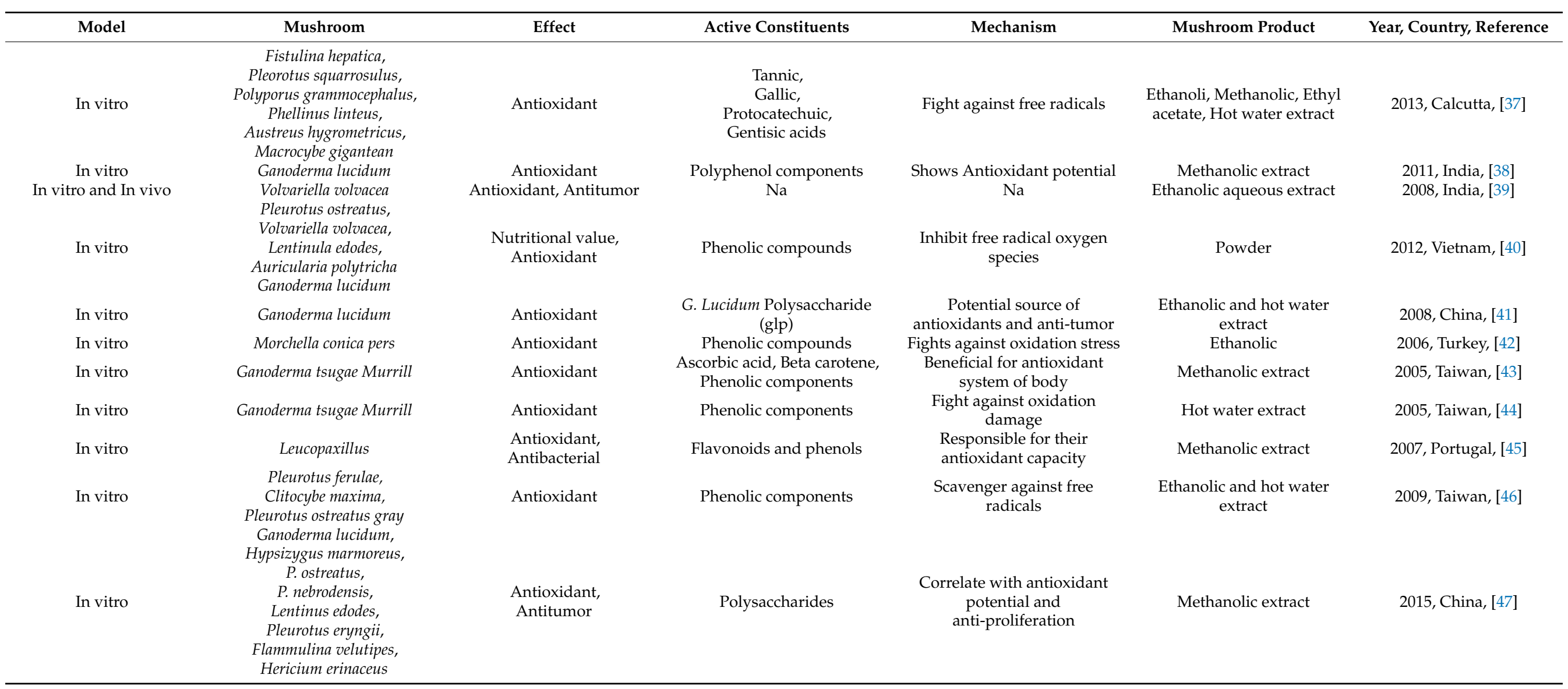




\section{Conclusions}

The present review article represents a summarized overview of the advancement of research in the area of structural as well as biological aspects of mushrooms. Recent advances in medicinal development have produced novel therapeutics to fight conventional complications. This study suggests that mushrooms are naturally occurring components, with numerous pharmacological activities capable of promoting human well-being. Mushrooms degrade matter to produce metabolites for life sustenance. They are also a relevant source of distinct molecules with metabolic diversity. Different species of mushrooms possess variable functionalities because of their individual specific bioactive components. Previous studies have shown that mushrooms possess complex biological activities, moderate to excellent antioxidant potential, and a variety of functions, especially with effects on the immune system. It has also been described as being effective as an antioxidant to control oxidative damage of cells, protective agent against cytotoxic materials, and in treating various metabolic disorders. Our review did not find sufficient evidence to justify the use of medicinal mushrooms as first line treatment for COVID-19. It remains uncertain whether it helps prolong long-term survival. However, mushrooms of the Basidiomycota species could be administered as an alternative adjunct to conventional treatment in consideration of its potential of augmenting stimulating host protection.

\section{Recommendation}

There is a promising source of medicinal mushrooms all over the world. The therapeutic dimensions of mushrooms are wide-ranging, which raises their importance globally. The expedition for new therapeutic agents has engaged mushrooms, providing a new route as an important source of knowledge, which has led toward different classes of compounds. Nowadays, experiments on structure-activity relationships of mushrooms and their effect on the scheme of novel drugs have rendered them one of the utmost cherished and thus substantial endeavors in the medicinal world. Our finding suggests that the G lucidum is an exceedingly effective antioxidant source; the results are in line with various previous data [63-69]. However, further research considering clinical data and human in vivo experiments are required. This information will help to the researchers and scientists to prepare high quality drugs based on the 3D structures. The hidden therapeutic potential could be decisive in present and future treatment.

Author Contributions: S.S., wrote the manuscript; S.-M.K. and M.A.K. help in answering reviewer comments; A.-Y.K. and M.I. help in graph and table perpetration; I.-J.L. supervised and financed the research. All authors have read and agreed to the published version of the manuscript.

Funding: This research was supported by the Basic Science Research Program through the National Research Foundation of Korea (NRF) funded by the Ministry of Education (2017R1D1A1B04035601).

Institutional Review Board Statement: Not applicable.

Informed Consent Statement: Not applicable.

Data Availability Statement: Not applicable.

Conflicts of Interest: The authors declare no conflict of interest.
Abbreviations
CCP Cantharellus cibarius polysaccharide.
CHO Cholesterol.
DLA Dalton's Lymphoma Ascites.
DPPH 2: 2-diphenyl-1-picrylhydrazyl.
EAC Ehrlich-Letter ascites carcinoma.
FRAP Fluorescence recovery after photobleaching
FTIR Fourier transform infrared spectroscopy. 


$\begin{array}{ll}\text { NAFLD } & \text { Nonalcoholic fatty liver disorder. } \\ \text { TAG } & \text { Triglyceride levels. } \\ \text { GEE } & \text { Ganoderma lucidum ethanol extract } \\ \text { HMG-COA } & \beta \text {-Hydroxy } \beta \text {-methylglutaryl-CoA }\end{array}$

\section{References}

1. Wasser, S.P. Current findings, future trends, and unsolved problems in studies of medicinal mushrooms. Appl. Microbiol. Biotechnol. 2011, 89, 1323-1332. [CrossRef]

2. Dai, Y.-C.; Yang, Z.-L.; Cui, B.; Yu, C.-J.; Zhou, L.-W. Species Diversity and Utilization of Medicinal Mushrooms and Fungi in China. Int. J. Med. Mushrooms 2009, 11, 287-302. [CrossRef]

3. Hobbs, C. Medicinal Mushrooms: An Exploration of Tradition, Healing, and Culture; Botanica Press: Summertown, TN, USA, 2002.

4. Yang, Q.; Jong, C. Medicinal mushrooms in China. Mushroom Sci. 1989, 1, 631-643.

5. Park, W.; Lee, H. Illustrated Book of Korean Medicinal Mushrooms; Kyo-Hak Publishing, Co.: Seoul, Korea, 1999.

6. Lindequist, U.; Niedermeyer, T.; Jülich, W.-D. The Pharmacological Potential of Mushrooms. Evid. Based Complement. Altern. Med. 2005, 2, 285-299. [CrossRef]

7. Ikekawa, T. Beneficial Effects of Edible and Medicinal Mushrooms on Health Care. Int. J. Med. Mushrooms $2001,3,3$.

8. Lee, P.C.; Bochner, B.R.; Ames, B.N. AppppA, heat-shock stress, and cell oxidation. Proc. Natl. Acad. Sci. USA 1983, 80, 7496-7500. [CrossRef] [PubMed]

9. Pullen, J.; Saeed, K. An overview of biodiesel oxidation stability. Renew. Sustain. Energy Rev. 2012, 16, 5924-5950. [CrossRef]

10. Halliwell, B.; Gutteridge, J.M. Free Radicals in Biology and Medicine; Oxford University Press: Oxford, UK, 2015.

11. Moskovitz, J.; Bin Yim, M.; Chock, P. Free Radicals and Disease. Arch. Biochem. Biophys. 2002, 397, 354-359. [CrossRef] [PubMed]

12. Pham-Huy, L.A.; He, H.; Pham-Huy, C. Free Radicals, Antioxidants in Disease and Health. Int. J. Biomed. Sci. IJBS 2008, 4, 89-96. [PubMed]

13. Hogg, N. Free Radicals in Disease. Semin. Reprod. Med. 1998, 16, 241-248. [CrossRef]

14. Liu, F.; Ooi, V.; Chang, S. Free radical scavenging activities of mushroom polysaccharide extracts. Life Sci. 1997, 60, 763-771. [CrossRef]

15. Mau, J.-L.; Chao, G.-R.; Wu, K.-T. Antioxidant properties of methanolic extracts from several ear mushrooms. J. Agric. Food Chem. 2001, 49, 5461-5467. [CrossRef] [PubMed]

16. Dinesh, R. The role of antioxidants and ROS scavenging machinery in wild mushrooms. In New and Future Developments in Microbial Biotechnology and Bioengineering; Elsevier: Amsterdam, The Netherlands, 2021; pp. 245-251.

17. Bamigboye, C.O.; Omomowo, I.O.; Alao, M.B.; Elegbede, J.A.; Adegoke, E. Free radical scavenging ability, mechanisms of action and health implications of oyster mushrooms (Pleurotus species): Pleurotus species (Oyster mushrooms): Free radical scavenging capacity. J. Microbiol. Biotechnol. Food Sci. 2021, 10, 636-647.

18. Rao, L.G.; Kang, N.; Rao, A.V. Polyphenol antioxidants and bone health: A review. In Phytochemicals-A Global Perspective of Their Role in Nutrition and Health; InTech: Rijeka, Croatia, 2012.

19. Rizzo, G.; Goggi, S.; Giampieri, F.; Baroni, L. A review of mushrooms in human nutrition and health. Trends Food Sci. Technol. 2021. [CrossRef]

20. Patocka, J.; Wu, R.; Nepovimova, E.; Valis, M.; Wu, W.; Kuca, K. Chemistry and Toxicology of Major Bioactive Substances in Inocybe Mushrooms. Int. J. Mol. Sci. 2021, 22, 2218. [CrossRef] [PubMed]

21. Hetland, G.; Johnson, E.; Bernardshaw, S.V.; Grinde, B. Can medicinal mushrooms have prophylactic or therapeutic effect against COVID-19 and its pneumonic superinfection and complicating inflammation? Scand. J. Immunol. 2021, 93, e12937. [CrossRef]

22. Uthan, E.T.; Senturk, H.; Uyanoglu, M.; Yamaç, M. First Report on the In Vivo Prebiotic, Biochemical, and Histological Effects of Crude Polysaccharide Fraction of Golden Chantharelle Mushroom, Cantharellus cibarius (Agaricomycetes). Int. J. Med. Mushrooms 2021, 23, 67-77. [CrossRef]

23. Kozarski, M.; Klaus, A.; Niksic, M.; Jakovljević, D.; Helsper, J.P.; Van Griensven, L.J. Antioxidative and immunomodulating activities of polysaccharide extracts of the medicinal mushrooms Agaricus bisporus, Agaricus brasiliensis, Ganoderma lucidum and Phellinus linteus. Food Chem. 2011, 129, 1667-1675. [CrossRef]

24. Badalyan, S.M. Edible and medicinal higher basidiomycetes mushrooms as a source of natural antioxidants. Int. J. Med. Mushrooms 2003, 5, 153-162. [CrossRef]

25. Mau, J.-L.; Lin, H.-C.; Chen, C.-C. Antioxidant Properties of Several Medicinal Mushrooms. J. Agric. Food Chem. 2002, 50, 6072-6077. [CrossRef]

26. Kim, M.-Y.; Seguin, P.; Ahn, J.-K.; Kim, J.-J.; Chun, S.-C.; Kim, E.-H.; Seo, S.-H.; Kang, E.-Y.; Kim, S.-L.; Park, Y.-J.; et al. Phenolic compound concentration and antioxidant activities of edible and medicinal mushrooms from Korea. J. Agric. Food Chem. 2008, 56, 7265-7270. [CrossRef]

27. Yang, J.-H.; Lin, H.-C.; Mau, J.-L. Antioxidant properties of several commercial mushrooms. Food Chem. 2002, 77, 229-235. [CrossRef]

28. Sulkowska-Ziaja, K.; Muszynska, B.; Motyl, P.; Pasko, P.; Ekiert, H. Phenolic compounds and antioxidant activity in some species of polyporoid mushrooms from Poland. Int. J. Med. Mushrooms 2012, 14, 385-393. [CrossRef] 
29. Turkoglu, A.; Duru, M.E.; Mercan, N.; Kivrak, I.; Gezer, K. Antioxidant and antimicrobial activities of Laetiporus sulphureus (Bull.) Murrill. Food Chem. 2007, 101, 267-273. [CrossRef]

30. Aziz, T.; Mehmet, E.D.; Nazime, M.; Ibrahim, K.; Kudret, G. Antimicrobial and antioxidant activities of mycelia of 10 wild mushroom species. J. Med. Food 2010, 13, 415-419.

31. Lee, I.-K.; Kim, Y.-S.; Jang, Y.-W.; Jung, J.-Y.; Yun, B.-S. New antioxidant polyphenols from the medicinal mushroom Inonotus obliquus. Bioorg. Med. Chem. Lett. 2007, 17, 6678-6681. [CrossRef]

32. Song, X.; Cai, W.; Ren, Z.; Jia, L.; Zhang, J. Antioxidant and Hepatoprotective Effects of Acidic-Hydrolysis Residue Polysaccharides from Shiitake Culinary-Medicinal Mushroom Lentinus edodes (Agaricomycetes) in Mice. Int. J. Med. Mushrooms 2021, 23, 85-96. [CrossRef]

33. Ebrahimzadeh, M.A.; Nabavi, S.M.; Nabavi, S.F.; Eslami, S. Antioxidant and Free Radical Scavenging Activities of CulinaryMedicinal Mushrooms, Golden Chanterelle Cantharellus cibarius and Angel's Wings Pleurotus porrigens. Int. J. Med. Mushrooms 2010, 12, 265-272. [CrossRef]

34. Wei, S.; Van Griensven, L.J.L.D. Pro- and Antioxidative Properties of Medicinal Mushroom Extracts. Int. J. Med. Mushrooms 2008, 10, 315-324. [CrossRef]

35. Woldegiorgis, A.Z.; Abate, D.; Haki, G.D.; Ziegler, G. Antioxidant property of edible mushrooms collected from Ethiopia. Food Chem. 2014, 157, 30-36. [CrossRef]

36. Liang, C.-H.; Ho, K.-J.; Huang, L.-Y.; Tsai, C.-H.; Lin, S.-Y.; Mau, J.-L. Antioxidant properties of fruiting bodies, mycelia, and fermented products of the culinary-medicinal king oyster mushroom, Pleurotus eryngii (higher Basidiomycetes), with high ergothioneine content. Int. J. Med. Mushrooms 2013, 15, 267-275. [CrossRef]

37. Khatua, S.; Paul, S. Acharya, K. Mushroom as the potential source of new generation of antioxidant: A review. Res. J. Pharm. Technol. 2013, 6, 3.

38. Mohsin, M.; Negi, P.S.; Ahmed, Z. Determination of the antioxidant activity and polyphenol contents of wild Lingzhi or Reishi medicinal mushroom, Ganoderma lucidum (W. Curt. Fr.) P. Karst. (higher Basidiomycetes) from central Himalayan hills of India. Int. J. Med. Mushrooms 2011, 13, 535-544. [CrossRef] [PubMed]

39. Mathew, J.; Sudheesh, N.P.; Rony, K.A.; Smina, T.P.; Janardhanan, K.K. Antioxidant and antitumor activities of cultured mycelium of culinary-medicinal paddy straw mushroom Volvariella volvacea (Bull.: Fr.) singer (agaricomycetideae). Int. J. Med. Mushrooms 2008, 10, 139-147. [CrossRef]

40. Nhi, N.; Hung, P. Nutritional composition and antioxidant capacity of several edible mushrooms grown in the Southern Vietnam. Int. Food Res. J. 2012, 19, 611.

41. Tseng, Y.-H.; Yang, J.-H.; Mau, J.-L. Antioxidant properties of polysaccharides from Ganoderma tsugae. Food Chem. 2008, 107, 732-738. [CrossRef]

42. Turkoglu, A.; Kivrak, I.; Mercan, N.; Duru, M.E.; Gezer, K.; Turkoglu, H. Antioxidant and antimicrobial activities of Morchella conica Pers. Afr. J. Biotechnol. 2006, 5, 1146-1150.

43. Mau, J.-L.; Tsai, S.-Y.; Tseng, Y.-H.; Huang, S.-J. Antioxidant properties of methanolic extracts from Ganoderma tsugae. Food Chem. 2005, 93, 641-649. [CrossRef]

44. Mau, J.-L.; Tsai, S.-Y.; Tseng, Y.-H.; Huang, S.-J. Antioxidant properties of hot water extracts from Ganoderma tsugae Murrill. LWT 2005, 38, 589-597. [CrossRef]

45. Barros, L.; Baptista, P.; Estevinho, L.M.; Ferreira, I.C.F.R. Bioactive properties of the medicinal mushroom Leucopaxillus giganteus mycelium obtained in the presence of different nitrogen sources. Food Chem. 2007, 105, 179-186. [CrossRef]

46. Tsai, S.-Y.; Huang, S.-J.; Lo, S.-H.; Wu, T.-P.; Lian, P.-Y.; Mau, J.-L. Flavour components and antioxidant properties of several cultivated mushrooms. Food Chem. 2009, 113, 578-584. [CrossRef]

47. Chen, P.; Yong, Y.; Gu, Y.; Wang, Z.; Zhang, S.; Lu, L. Comparison of antioxidant and antiproliferation activities of polysaccharides from eight species of medicinal mushrooms. Int. J. Med. Mushrooms 2015, 17, 287-295. [CrossRef] [PubMed]

48. Xiao, J.-H.; Xiao, D.-M.; Chen, D.-X.; Xiao, Y.; Liang, Z.-Q.; Zhong, J.-J. Polysaccharides from the Medicinal MushroomCordyceps taiiShow Antioxidant and Immunoenhancing Activities in aD-Galactose-Induced Aging Mouse Model. Evid. Based Complement. Altern. Med. 2012, 2012, 1-15. [CrossRef]

49. Wong, J.Y.; Chye, F.Y. Antioxidant properties of selected tropical wild edible mushrooms. J. Food Compos. Anal. 2009, 22, 269-277. [CrossRef]

50. Ferreira, I.C.; Barros, L.; Abreu, R. Antioxidants in wild mushrooms. Curr. Med. Chem. 2009, 16, 1543-1560. [CrossRef]

51. Elisashvili, V. Submerged cultivation of medicinal mushrooms: Bioprocesses and products. Int. J. Med. Mushrooms 2012, 14, 211-239. [CrossRef] [PubMed]

52. Sujata, W.; Devi, S.N.; Mandal, S.C. Phytochemicals and Investigations on Traditionally Used Medicinal Mushrooms. In Evidence Based Validation of Traditional Medicines; Springer: Berlin/Heidelberg, Germany, 2021; pp. 965-984.

53. Jain, A.; Ganeshpurkar, A.; Rai, G. Medicinal mushrooms: Towards a new horizon. Pharmacogn. Rev. 2010, 4, 127-135. [CrossRef]

54. Ajith, T.A.; Janardhanan, K.K. Indian medicinal mushrooms as a source of antioxidant and antitumor agents. J. Clin. Biochem. Nutr. 2007, 40, 157-162. [CrossRef]

55. De Silva, D.D.; Rapior, S.; Hyde, K.D.; Bahkali, A. Medicinal mushrooms in prevention and control of diabetes mellitus. Fungal Divers. 2012, 56, 1-29. [CrossRef] 
56. Adeyi, A.O.; Awosanya, S.A.; Adeyi, O.E.; James, A.S.; Adenipekun, C.O. Ganoderma lucidum ethanol extract abrogates metabolic syndrome in rats: In vivo evaluation of hypoglycemic, hypolipidemic, hypotensive and antioxidant properties. Obes. Med. 2021, 22, 100320. [CrossRef]

57. Lotfy, T.M.R.; El-Hendy, H.A.R.; Shawir, S.M.S. Effect of Mushroom, Oat and Their Mixtures as Functional Foods on Antioxidant Activities, Hematological Parameters of Obese Rats and its Sensory Evaluation. Alex. Sci. Exch. J. 2021, 42, 21-36.

58. Al-Faqeeh, L.A.S.; Naser, R.; Kagne, S.R.; Khan, S.W. Activity of mushrooms against diabetic and inflammation: A review. GSC Biol. Pharm. Sci. 2021, 14, 37-44. [CrossRef]

59. Martinez-Medina, G.A.; Chávez-González, M.L.; Verma, D.K.; Prado-Barragán, L.A.; Martínez-Hernández, J.L.; Flores-Gallegos, A.C.; Thakur, M.; Srivastav, P.P.; Aguilar, C.N. Bio-funcional components in mushrooms, a health opportunity: Ergothionine and huitlacohe as recent trends. J. Funct. Foods 2021, 77, 104326. [CrossRef]

60. Rani, A.; Saini, K.; Bast, F.; Mehariya, S.; Bhatia, S.; Lavecchia, R.; Zuorro, A. Microorganisms: A Potential Source of Bioactive Molecules for Antioxidant Applications. Molecules 2021, 26, 1142. [CrossRef]

61. Wachtel-Galor, S.; Tomlinson, B.; Benzie, I.F.F. Ganoderma lucidum ('Lingzhi'), a Chinese medicinal mushroom: Biomarker responses in a controlled human supplementation study. Br. J. Nutr. 2004, 91, 263-269. [CrossRef] [PubMed]

62. Lo, H.-C. Bioactive components and possible activities of medicinal mushrooms in alleviating the pathogenesis of nonalcoholic fatty liver disease. Int. J. Med. Mushrooms 2021, 23, 29-41. [CrossRef]

63. Lu, J.; He, R.; Sun, P.; Zhang, F.; Linhardt, R.J.; Zhang, A. Molecular mechanisms of bioactive polysaccharides from Ganoderma lucidum (Lingzhi), a review. Int. J. Biol. Macromol. 2020, 150, 765-774. [CrossRef]

64. Rahman, M.A.; Al Masud, A.; Lira, N.Y.; Shakil, S. Proximate analysis, phtochemical screening and antioxidant activity of different strains of Ganoderma lucidum (Reishi mushroom). Open J. Biol. Sci. 2020, 5, $24-27$.

65. Ryu, D.H.; Cho, J.Y.; Bin Sadiq, N.; Kim, J.-C.; Lee, B.; Hamayun, M.; Lee, T.S.; Kim, H.S.; Park, S.H.; Nho, C.W.; et al. Optimization of antioxidant, anti-diabetic, and anti-inflammatory activities and ganoderic acid content of differentially dried Ganoderma lucidum using response surface methodology. Food Chem. 2021, 335, 127645. [CrossRef]

66. Al-Faqeeh, L.A.S.; Naser, R.; Kagne, S.R.; Khan, S.W. Nutritional values, ethno-medicinal uses and antioxidant activity of mushrooms: A review. Eur. J. Biomed. 2021, 8, 292-300.

67. Sun, J.; He, H.; Xie, B.J. Novel antioxidant peptides from fermented mushroom Ganoderma lucidum. J. Agric. Food Chem. 2004, 52, 6646-6652. [CrossRef] [PubMed]

68. Radhika, R.; Sundar, S.K.; Anuradha, R.; Radhika, R.; Sundar, S.K.; Anuradha, R. Antioxidant Property of Fruiting Bodies of Ganoderma Lucidum. Int. J. Mod. Agric. 2021, 10, 3508-3514.

69. Bhat, Z.A.; Wani, A.H.; War, J.M.; Bhat, M.Y. Major bioactive properties of ganoderma polysaccharides: A review. Asian J. Pharm. Clin. Res. 2021, 14, 11-24. [CrossRef] 